\title{
Vertebral prosthetic arthrodesis migration to the esophageal lumen: a rare cause of dysphagia
}

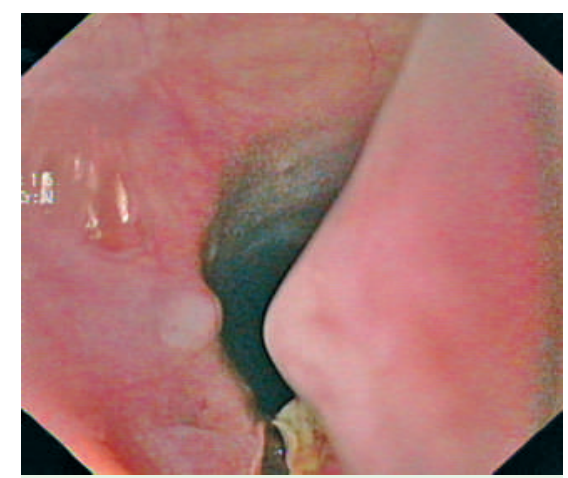

Figure 1 Extrinsic compression at the level of cervical esophagus with normal appearing mucosa.

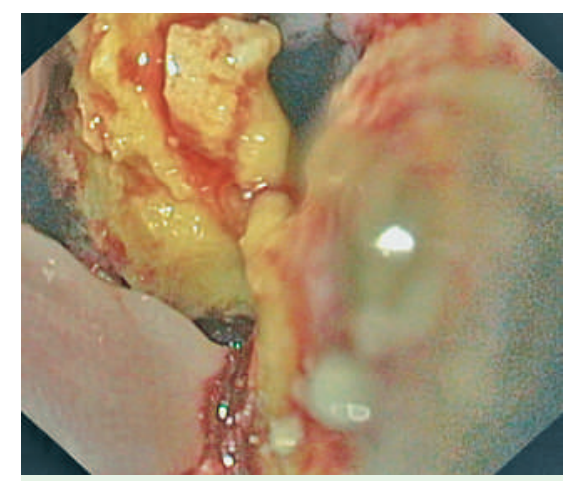

Figure 2 Foreign body in the lumen of the cervical esophagus.

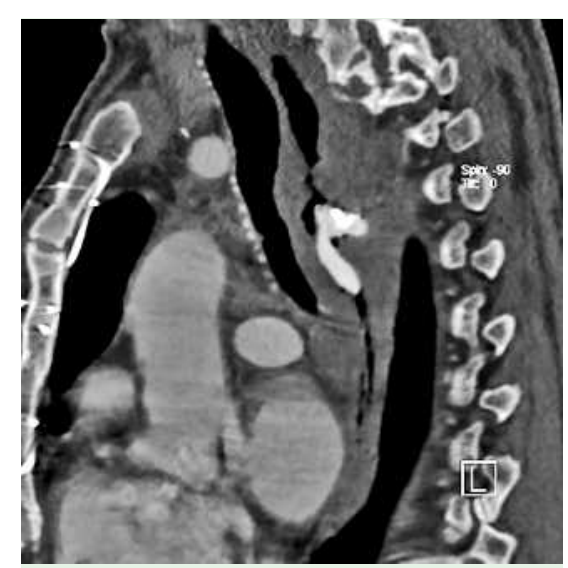

Figure $3 \mathrm{CT}$ image showing residual arthrodesis partially inserted in the esophageal wall (with a severe inflammatory reaction), and in the interior of the lumen.
A 52-year-old man was referred because of progressive dysphagia. He had a past medical history of recurrent spinal hydatidosis at the D1 - 2 level, which was surgically treated in 2000 and 2002 with a total corporectomy of the D1 vertebrae, removal of cysts, arthrodesis with a Moss prosthesis, and insertion of a titanium implant. In 2004, computed tomography (CT) showed the migration of the prosthesis to the posterior mediastinum. The patient underwent repeat surgery but the prosthetic arthrodesis could be only partially removed. One year later, he complained of moderate dysphagia. An upper endoscopy was performed, showing an extrinsic compression at the level of cervical esophagus with normal appearing mucosa ( Figure 1). Because of progression of dysphagia, a second upper endoscopy was performed 6 months later, and revealed a foreign body in the lumen of the esophagus, at the level of the previous extrinsic compression, that was impossible to mobilize ( $\bullet$ Figure 2 ).

The CT image confirmed that the foreign body was the residual arthrodesis, which had progressed through the posterior mediastinum, and had eroded the esophageal wall ( Figure 3). Using CT, it was also possible to identify a fistulous tract from the D1-2 level to the esophagus, which was the pathway followed by the arthrodesis when migrating to the esophageal lumen. The patient underwent surgery, and the residual arthrodesis was removed without complications.

Hydatid disease is relatively common in the Mediterranean area, but bone hydatidosis is rare and occurs in $1-2.5 \%$ of cases of human hydatidosis [1,2]. About $50 \%$ of cases of bone hydatidosis are spinal $[3,4]$. Surgery is the treatment of choice, with removal of the affected vertebrae combined with prosthetic bone fixation. To our knowledge, this is the first case reported with migration of the vertebral prosthetic arthrodesis eroding the esophageal wall and, therefore, represents an unusual case of dysphagia.

Endoscopy_UCTN_Code_CCL_1AB_2AF

Endoscopy_UCTN_Code_CCL_1AB_2AC_3AH
G. Fernández-Esparrach ${ }^{1}$,

A. Z. Gimeno-García ${ }^{1}$, J. R. Ayuso²,

À. Ginès ${ }^{1}$, J. M. Bordas ${ }^{1}$

1 Endoscopy Unit, Institut de Malalties Digestives, Hospital Clínic, IDIBAPS. University of Barcelona, Spain

2 Radiology Unit, Institut de Malalties Digestives, Hospital Clínic, IDIBAPS,

University of Barcelona, Spain

\section{References}

1 Szypryt EP, Morris DL, Mulholland RC. Combined chemotherapy and surgery for hydatid bone disease. J Bone Joint Surg Br 1987; 69: $141-144$

2 Zlitni M, Ezzaouia Z, Lebib $H$ et al. Hydatid cyst of bone: diagnosis and treatment. World J Surg 2001; 25: 75-82

3 Govender TS, Aslam M, Parbhoo A et al. Hydatid disease of the spine. Clin Orthop Relat Res 2000; 378: $143-147$

4 Herrera A, Martínez AA, Rodríguez J. Spinal hydatidosis. Spine 2005; 30: 2439-2444

Bibliography

DoI $10.1055 / \mathrm{s}-2007-966102$

Endoscopy 2007; 39: E188-E188

(c) Georg Thieme Verlag KG Stuttgart · New York . ISSN 0013-726X

Corresponding author

G. Fernández-Esparrach, MD

Endoscopy Unit

Institut de Malalties Digestives

Hospital Clínic

Villarroel 170

08036 Barcelona

Spain

Fax: +34-93-2279387

mgfernan@clinic.ub.es 